$Q_{p}^{\prime}$ the leat effect of this reaction is not known with any certainty, due primarily to the dissociation of the iodine molecule into atoms at even moderate temperatures.' Since the heat of reaction at all events is small, in order to calculate $\mathrm{K}^{\prime}$ with some degree of accuracy, it would probably be necessary here to take into account higher terms than $T^{2}$ in the original deduction. It can, however, be seen qualitatively in the equation by using a small value for the heat of reaction, that there is marked dissociation at comparatively low temperatures, but its change with increasing temperature cannot be followed.

I.ABORATURy OF PHysical Chemistry.

[CONTRIBUTIONS FROA THE LABORATORY OF THE MAILINCKRODT CHEMICAL, WORKS].

\title{
ON THE DENSITY CURVE OF MIXTURES OF BROMINE AND CHLORINE. ${ }^{2}$
}

BY IAUYCELOT W. ANIREWS AND HENRY A, CARLTON.

Received February 23, 1907.

The fullest determinations of the densities of bromine at various temperatures appear to be those of Thorpe ${ }^{3}$ and of Pierre*. The former determined the density at $0^{\circ}$ to be 3.187 , while Pierre found at the same temperature 3.I88. At $35^{\circ}$ Thorpe found 3.10104 and Pierre 3.10472. We shall bring forward evidence in the present paper going to show that the results of Thorpe are too low by an amount which can be accounted for on the assumption that his bromine contained about 0.039 per cent. of chlorine. The density of liquid chlorine at $25^{\circ}$, as calculated from the formula of $\mathrm{Knietsch}^{6}$, is $\mathrm{I} \cdot 39778$. The existence of a monochloride of bromine is generally assumed, on the basis of the investigations of Bornemann". There seems to be but little evidence to support this assumption, except the existence at low temperatures of hydrates, said ${ }^{8}$ to have the formulas, $\mathrm{BrCl} .5 \mathrm{H}_{2} \mathrm{O}$ and $\mathrm{BrCl} \cdot{ }_{1} \mathrm{H}_{2} \mathrm{O}$. Obviously the existence of such hydrates, even if fully demonstrated, would constitute no sufficient proof of the existence of the compound $\mathrm{BrCl}$ in the absence of water. Proof or disproof of the existence of compounds of chlorine and of bromine with one another must be sought for in the physical properties and behavior of mixtures of these elements at ordinary or at low temper-

${ }^{1}$ See the discussion by Haber, 1. c. page 100.

${ }^{2}$ Read at the New York Meeting of the American Chemical Society.

"J. Chem. Soc., 37, 172 (1880).

+Moissan, Traité. de chimie minérale, Tome I, I33; Ann. chim. phys., (3) 20, $45(18+7)$.

SInterpolated.

${ }^{6}$ Ann., 259, I00 ( I 890$)$.

'A111., 189, 206 (I877).

"Loewig, Das Brom, Heideil)erg (1829) 64 . 
atures. Among the properties to be taken into consideration in this connection is that of density. If it should appear that these elements mix without contraction of volume, that fact alone would be strong presumptive evidence against the existence of a compound. The chief object with which the authors undertook an investigation of the density curve of chlorine-bromine mixtures was a purely practical one. A simple preliminary calculation showed that, unless a very considerable contraction occurs on mixing chlorine with bromine, small percentages of chlorine must so greatly reduce the density of bromine as to make it possible to base on the density alone a determination of the chlorine with the prospect of very satisfactory results. This anticipation was fully realized.

In the density determinations three pycnometers were used by the authors, of which two were of the well-known Squibb type, with narrow divided stem, ground into the body, of 50 and $25 \mathrm{cc}$. respectively.

The values of the stem divisions were found by calibration with mercury, the capacity of the bulbs by weighing with water. The third instrument, made by Koehler, of $35 \mathrm{cc}$. capacity (nominal), is a constant volume instrument with the thermometer fused in the bulb. The readings of this, as of all other thermometers used, were carefully controlled.

It was not found possible by re-grinding the joints of the Squibb pycnometers to absolutely prevent evaporation of bromine. The loss was, however, small and was checked by weighing both before snd after acquiring the temperature at which the scale reading was taken. It was observed that in two of these instruments the weight of the bromine caused the bottom of the bulb to bulge a little, increasing the volume above what it was when calibrated with water. The amount of this error was determined by immersing the pycnometer, filled with bromine, in a liquid of about the same density (acetylene tetrabromide) and comparing the reading with that obtained when the instrument was immersed in water, both liquids being in the same thermostat at identical temperatures. The maximum error due to this cause amounted to about five units in the fifth decimal place. No attempt was made to correct for it. If greater accuracy should be ained at in future work, only pycnometers of spherical form, made rather thick in the wall and not flattened at the bottom should be used. Very accurate thermometer readings would then become necessary. Some of the determinations referred to below were made at various temperatures between $25^{\circ}$ and $32^{\circ}$. Those which were relied on for determinations of the constants of the formula were made in a thermostat within a few tenths of a degree of $25^{\circ}$, so that the correction for reduction to this temperature was small.

The weights used were corrected by comparison with a set of which a table of corrections had recently been furnished by the Bureau of Stand- 
ards. Two thermometers were used. Their readings were reduced to the international hydrogen standard, on the basis of comparison with an instrument standardized by the Reichsanstalt and further controlled by observations at the zero point and at the transition point of sodium sulphate (after Richards). Both harmonized well. They were divided into $1 / 5^{\circ}$ but were read with a glass to $1 / 50$, with a probable error of about this amount. In consequence of the high coefficient of expansion of bromine, uncertainties in the temperature determinations become the chief source of error and practically set the limit to the accuracy of the results obtained.

The apparent coefficient of expansion of bromine in glass over the range $25^{\circ}$ to $30^{\circ}$ was found by us to be 0.00110 , in excellent agreement with the results of Thorpe. ${ }^{\prime}$ This factor was used in reducing observations made at other temperatures to the $25^{\circ}$ standard and we have assumed it to be valid for the impure as well as for the pure bromine. That this assumption is not too far from the truth within the limits of concentratinn to which it was applied is confirmed by a single determination of the coefficient for a bromine containing about five per cent. of chlorine, which gave the value, $0.00 \mathrm{I} 28$.

The density of pure bromine was determined on four preparations, made from material derived from different sources and purified by different methods. The results are : series $A, 3.1022-3.1019-3.1022-$ 3.1019; series B, 3.10143-; series C, 3.10218--3.10230; series D, 3. $1025-3.1027-3.1025$. Preparation B was partially frozen (melting point $-7^{\circ} .1$ ), the liquid portion poured off and the crystals used for the determination. An accident prevented its further examination, but although the density found is certainly too low, the figures are given, since the cause of the error is unkuown. Series D is regarded as the most reliable, because the temperature determinations are nore precise, the temperature corrections much smaller, and, further, because the material was shaken with calcium carbonate to remove possible traces of hydrobromic acid. In series $A$ the bromine was dried with sulphuric acid, in the other series with phosphoric anhydride. Preparations $A$ and D were known to be chlorine-free. They were tested by the method recently given by one of us. ${ }^{2}$ Equal confidence is felt that preparations $A$ and $B$ were also free from chlorine because of the guarantee afforded in the light of our experience with the method of preparation employed. The melting point of preparations $A . C$ and $D$ was $7^{\circ} .0$ and the boiling point $5^{\circ} .7$ at $703 \mathrm{~mm}$.

Probably the most persistent contamination of bromine is hydrobromic acid. We have not been able to devise any method for its removal which

${ }^{1}$ loc, cit.

2 This Journal 29, 275. 
is not open to criticism. It should be said that preparation $D$, after drying etc., was redistilled in two large fractions and a third, smaller, one. The first two had identical densities, the third a slightly lower one. Perhaps it is permissible to assume that all or a great part of the hydrobromic acid originally present was concentrated in the last fraction.

If double weight is assigned to series $D$ and the one doubtful observation of series B is not omitted from consideration, we obtain as the most probable value of the density of pure dry bromine from our observations

$$
\mathrm{D}_{4^{\circ}}^{25^{\circ}}=3.10227 \text {. }
$$

With the aid of this constant for bromine and of the corresponding figure for chlorine of Knietsch previously referred to, the theoretical relation of chlorine percentage $(p)$, in a mixture of the two elements, to the density at $25^{\circ} \mathrm{a}(d)$ of the mixture is given by the formula:

$$
p=82.005\left(\frac{3.10227}{d}-\mathrm{I}\right)
$$

on the assumption that no contraction occurs. We find that an expression of the same form, with a change in the coefficient of the second term reproduces the observation values very well; to wit:

$$
p=88.593\left(\frac{3.10227}{d}-\mathrm{I}\right)=\frac{274.840}{d}-88.593
$$

When the mixture is saturated with water, the formula becomes:

$$
p=88.59\left(\frac{3.1004}{d}-\mathrm{r}\right)=\frac{274.665}{d}-88.59
$$

The last expression (3) must be regarded as merely approximate in character since, as is well known, bromine and water react, producing hydrobromic acid and hypobromous acid. Hence, with the duration of contact the apparent solubility of water in the bromine steadily increases. When the relative amount of water is small the phenomenon is most marked and the density of the bromine continues to decrease for a long time as it takes up hydrobromic acid and water. Equation (3) is approximately correct for bromine which has been quickly saturated at $25^{\circ}$ with water by violent shaking.

The degree of precision of equation (2) when applied to mixtures of

\begin{tabular}{|c|c|c|c|c|}
\hline $\begin{array}{c}\text { Per cent. } \\
\text { by analysis } \\
4.388 \\
4.46 \mathrm{I}\end{array}$ & $\begin{array}{c}\text { Density } \\
\text { dry }\end{array}$ & $\begin{array}{l}\text { Per cent. } \\
\text { by Eq. } 2\end{array}$ & $\begin{array}{c}\text { Density } \\
\text { wet }\end{array}$ & $\begin{array}{l}\text { Percent. } \\
\text { by Eq. } 3\end{array}$ \\
\hline $\left.\begin{array}{l}4.439 \\
4.442 \\
4.407 \\
4.401\end{array}\right\}$ & 2.9553 & 4.406 & 2.9535 & 4.406 \\
\hline $\left.\begin{array}{l}7.741 \\
7.717 \\
7.198\end{array}\right\}$ & 2.8533 & 7.730 & $\begin{array}{l}2.85 \text { I } 2 \\
2.866 \text { I }\end{array}$ & $\begin{array}{l}7.743 \\
7.242\end{array}$ \\
\hline This Jour & & & & \\
\hline
\end{tabular}
pure bromine with pure chlorine is shown by the following comparison of the chlorine percentages of such mixtures as deduced by analysis ${ }^{1}$ and as calculated by the formulas from the observed densities. 
The organic and other impurities, anide from chlorine, which are usually present in crude bromine, do not rery seriously influence the results of the density determinations, as may be seen from the following analyses of material of this sort.

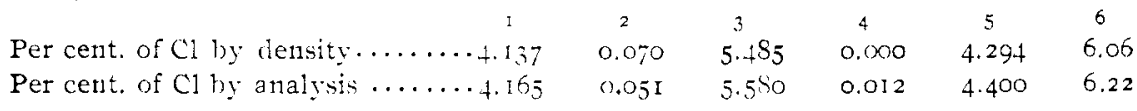

It is possible, therefore, to determine from the density of a sample of bromine the amount of chlorine it contains with sufficient accuracy for almost any purpose and in much less time than by any chemical method.

The contraction that occurs on mixing (liquid) chlorine with bromine can be readily calculated from Eq. (2). The validity of this formula has only been tested to I I per cent. of chlorine, but if we extrapolate to 30 per cent. (corresponding in composition approximately to $\mathrm{BrCl}$ ) it gives for the corresponding density 2.4175 , whereas, if no contraction occurred the density would be $2.27 \mathrm{r} 3$. The contraction amounts, accordingly, to about two per cent. of the total volume, a result that appreciably increases the probability that actual chemical combination does take place between these elements to a limited extent.

In conclusion, we present the following comparison of the densities of bromine at several temperatures as found by Thorpe and by Pierre with our own results.

\begin{tabular}{|c|c|c|c|}
\hline remp. C & $\begin{array}{c}\text { Pierre } \\
(1847)\end{array}$ & $\begin{array}{l}\text { Thorpe } \\
\text { (1880) }\end{array}$ & $\begin{array}{r}\text { A. and } C . \\
(1906)\end{array}$ \\
\hline $0^{\circ}$ & 3.188 & 3.187 & $\ldots$ \\
\hline $20^{\circ}$ & 3.12 I $(45)$ & $3.1 \pm 8(4.3)$ & 3. I 1932 \\
\hline $25^{\circ}$ & $3.104(72)$ & $3 . \operatorname{IOI}\left(0_{4}\right)$ & 3.10227 \\
\hline $30^{\circ}$ & $\ldots \ldots$ & $\ldots \ldots \ldots$ & 3.08479 \\
\hline
\end{tabular}

St. Louis, Dec. 24, 1906.

\section{COMBINATIONS OF THE SESQUIOXIDES WITH THE ACID MO- LYBDATES}

R. D. FAIL.

Received February 23, 1906.

Since the pioneer work of Marignac, Gibbs and others on the complex inorganic acids and their derivatives, a large number of these compounds have been prepared and studied. By far the greater number are salts whose acid portion is composed of molybdic or tungstic trioxide in combination with acid oxicles of the type $\mathrm{R}_{2} \mathrm{O}_{5}$ or $\mathrm{RO}_{2}$ and with a base of the type $\mathrm{RO}$ or $\mathrm{R}_{2} \mathrm{O}$. The tendency of molybdic and tungstic oxides to form salts of poly acids is strong, we have for example the salts $\mathrm{Na}_{2} \mathrm{O}_{4} \mathrm{MoO}_{3}$, $3 \mathrm{~K}_{2} \mathrm{O} .7 \mathrm{MOO}_{3}$. $5 \mathrm{Na}_{2} \mathrm{O} . \tau 2 \mathrm{WO}_{3}, \mathrm{Na}_{2} \mathrm{O} .4 \mathrm{WO}_{3}$, etc., which contain a combination of several molectles of the molybdic or tungstic oxides as the acid. If, in these salts, part of the $\mathrm{RO}$, oxide is replaced by an oxide of 